NBER WORKING PAPER SERIES

\title{
CORPORATE FINANCIAL POLICY, TAXES, AND UNCERTAINITY: AN INTEGRATION
}

Alan J. Auerbach

and

Mervyn A. King

Working Paper No. $\underline{324}$

NATIONAL BUREAU OF ECONOMIC RESEARCH 1050 Massachusetts Avenue

Cambridge MA 02138

March 1979

The research reported here is part of the NBER's research program in Business Taxation and Finance. Any opinions expressed are those of the authors and not those of the NBER. Financial support of the NBER is gratefully acknowledged. 
CORPORATE FINANCIAL POLICY, TAXES, AND UNCERTATNTY: AN INTEGRATION

\section{Surmary}

In this paper, we present a simple general equilibrium model of the portfolio behavior of households and institutions, paying particular attention to the influence of differences in tax rates and attitudes toward risk. Under the Dlausible assumptions that households are more risk averse than institutions and possess a greater relative "tax preference" for equity versus debt, we are able to characterize the equilibria which may result when debt is subject to bankruptcy risk.

Among the issues which we study are the effects of tax rate changes, changes in risk, and changes in firm leverage on the relative asset holdings of the two types of investor and the rates of return earmed on equity and debt. Numerical simulations provide additional understanding of the model's characteristics.

Alan J. Auerbach

National Bureau of Economic Research 1050 Massachusetts Avenue

Cambridge, MA 02138
Mervyn A. King

The University of Bimingham Department of Economics Birmingham B15 2TT ENGLAND 


\section{Introduction}

The relationship between the ownership of corporate securities (both debt and equity) and the financial policy of the company is complex, and causation runs in both directions. Given the tax rates paid by its shareholders, the firm will be able to calculate the optimal financial policy, and given the policy of the firm, market equilibrium will determine a certain pattern of shareholdings. To analyze how alternative tax systems will affect portfolio decisions of both firms and investors, we need to solve the complete general equilibrium model. A further reason for wishing to look at the general equilibrium is that, provided the conditions necessary for the Modigliani-Miller theorem to hold are satisfied, although the debt-equity ratio of an individual firm may be a matter of indifference, there may exist an equilibrium aggregate debt-equity ratio for the corporate sector as a whole.

Most work on taxation and share ownership has assumed that investors pay a common tax rate on each form of income. If we extend this to a world in which investors pay different marginal tax rates then, under perfect certainty, we obtain an equilibrium with investors specializing in those securities which are optimal, given their tax rates. ${ }^{1}$ Mixed portfolios requires, in general, the existence of uncertainty. We wish to focus on a model in which investors face different tax rates but still hold diversified portfolios. To do this, we need a model which allows for both taxes and uncertainty.

In this paper, we describe and analyze a simple general equilibrium model with taxes and uncertainty. The rate of return on capital is random, and we wish to know how the claims on the return will be divided between debt and equity. The equilibrium will be characterized by the interest rate offered on corporate debt, the debt-equity ratio, and the relative holdings of debt and equity by different investors. 
The usual portfolio approach to investor behavior, which utilizes the capital Asset Pricing Mode ${ }^{2}$, cannot be applied directly here because the variances and covariances of securities are endogenous to the model. Furthermore, the possibility of bankruptcy means that the model is rather difficult to handle mathematically.

\section{The Model}

We consider a two-period model with two types of investor, a household sector $(\mathrm{H})$ which is risk averse and an institutional sector which comprises a large number of tax-exempt institutions (I), such as pension funds, which are risk-neutral. Households and institutions allocate fixed initial wealth among two types of asset, corporate equity (E) and corporate debt (D). If we denote $v_{j}^{i}$ as the value of sector i's holding of asset $j$, then the balance sheet constraint implies

$$
w^{i}=v_{D}^{i}+v_{E}^{i} \quad i=H, I
$$

The total market value of security $j$ is

$$
v_{j}=v_{j}^{H}+v_{j}^{I} \quad j=D, E
$$

and total wealth is normalized to unity:

$$
w^{H}+w^{I}=1
$$

We shall assume that households and institutions are quite distinct and we shall ignore any links between the two groups. The portfolio decisions of households are made independently of the way any money which may have been 
invested by institutions on their behalf is invested by the managers of such institutions. The reaction of the level of private household saving to changes in institutional saving can be modeled by varying the relative levels of initial wealth. We believe this to be a reasonable way to model the role of pension funds. More debatable perhaps is the assumption that institutions are riskneutral, but it is useful in showing how the model behaves when households are more risk-averse than institutions, and without it the model is much less tractable. Relaxing the assumption would not alter the qualitative nature of the results which we present below.

Wealth in this economy is held in the form of financial claims on the real capital stock which is the sole input to production. We assume that there is a single firm in the economy which we may think of as representing the corporate sector. In the first period, the firm decides on the fraction of the value of claims which will be sold in the form of debt and the fraction to be sold as equity. In other words, it decides on the debt-equity ratio. It has no decision to make about real variables. Given this decision, households and investors will allocate their wealth between the two securities. In the second period, profits will be realized and will depend upon the state of the world. We shall assume that there are only two possible states of the world. In the first state, profits (before tax) are $M_{1}$, and in the second, $M_{2}\left(M_{2}>M_{1}\right)$. The probability of the favorable outcome, state 2 , is agreed by all investors to be $\mathrm{p}$. For ease of notation we may let the rate of return on capital in state $\theta$ be described by $\theta$. If the nominal interest rate on corporate debt is $\mathrm{R}$ then, given the assumptions of limited liability and tax deductibility of interest payments, the rate of return on equity is given by 


$$
\begin{aligned}
r_{E}(\theta) & =\frac{\left(1-t_{C}\right)\left(\theta-R v_{D}\right)}{v_{E}} & & \text { if } \theta \geq R v_{D} \\
& =0 & & \text { if } \theta<R v_{D}
\end{aligned}
$$

where $t_{c}$ is the corporate tax rate. Similarly, the rate of return on corporate debt is:

$$
\begin{aligned}
r_{D}(\theta) & =R & & \text { if } \theta \geq R v_{D} \\
& =\frac{\theta}{v_{D}} & & \text { if } \theta<R v_{D}
\end{aligned}
$$

where allowing for taxes, personal and corporate, and assuming zero bankruptcy costs, the consumption of the two groups is given by

$$
\begin{aligned}
& C^{H}(\theta)=r_{D}(\theta) v_{D}^{H}\left(1-t_{p}\right)+r_{E}(\theta) v_{E}^{H}\left(1-t_{e}\right) \\
& C^{I}(\theta)=r_{D}(\theta) v_{D}^{I}+r_{E}(\theta) v_{E}^{I}
\end{aligned}
$$

where

$$
\begin{aligned}
t_{p}= & \text { rate of personal tax on interest income } \\
t_{e}= & \text { rate of personal tax on equity income, which may be thought of } \\
& \text { as an average of the tax rates on dividends and capital gains; } \\
& \text { hence, we assume } t_{e} \text { is strictly less than } t_{p} .
\end{aligned}
$$

In period one, investors allocate initial wealth among the two assets in order to maximize the expected utility of second-period consumption. Since institutions are risk-neutral they will maximize the expected value of (7) and, hence, will allocate all their wealth to the asset with the higher expected rate of return, except in the case where the expected rates of return are equal, when they are indifferent. Households are assumed to maximize the expected utility of a concave utility function defined on consumption as given by (6). Both groups of investors will take the interest rate $R$ and the debt-equity ratio $\left(\frac{v_{D}}{1-v_{D}}\right)$ as given. 
In addition to the balance sheet constraints given by (1), we shall place some non-negativity constraints on the value of security holdings. Since institutions are risk-neutral, we need some constraints to rule out infinite holdings and short sales, ans so we shall assume throughout that

$$
v_{j}^{I} \geq 0 \quad j=D, E
$$

It may or may not seem reasonable to rule out short sales of equity and debt by households, and we shall discuss the implications of imposing such constraints later.

At this point, we should explain the relationship between our model and the assumptions of the Modigliani - Miller theorem. We have assumed that all wealth in the economy is invested in a single firm, and, thus, by definition the value of the firm is always unity. In this trivial sense the value of the firm is independent of the debt-equity ratio. But, more fundamentally, we may ask whether an investor's expected utility is a function of the debt-equity ratio. In our model investors are indifferent to the choice of debt-equity ratio provided that there are no taxes and no binding non-negativity constraints on the levels of security holding. This is true even though bankruptcy may occur. The reason is that debt and equity provide two linearly independent assets which span the consumption possibility set given by technology because we have only two states of the world. If we were to add a third state of the world, the debtequity ratio would matter even in the absence of taxes and constraints.

For investors to engage in "homemade diversification", they must be able to sell short either debt or equity as circumstances require. If we rule out short sales, the debt-equity ratio may matter and, of course, the introduction of taxes means that investors have preferences over the choice of debt-equity 
ratio. As we shall see, it is likely that investors will disagree about the optimal debt-equity ratio for the firm.

The system we have described contains seven unknowns, corresponding to the four values of security holdings $v_{j}^{i}$, the total values of debt and equity, and the coupon rate on corporate bonds. The first-order conditions for portfolio optimization give two independent equations, and there are four accounting constraints in (1) and (2). The remaining equation needed to close the system describes the behavior of the firm. It has to determine the value of bonds which it will sell which is equivalent to choosing the debt-equity ratio. Although, one might argue that this will be chosen "in the interests of the shareholders," such a criterion is ambiguous here because, in general, households and institutions will disagree as to what constitutes the "optimal" debtequity ratio. We shall discuss later the various criteria which might be used to determine the value of the debt-equity ratio, but for the moment we shall proceed on the assumption that it is given.

\section{Types of Equilibria}

At this stage we shall describe the types of equilibria which are feasible and characterize them in terms of the relative holdings of the two assets by the two types of investor. We shall then explore how changes in taxation and uncertainty affect the outcomes. There are three types of "super-regime" which are characterized by:
(a) riskless debt debt
$\mathrm{Rv}_{\mathrm{D}}<\mathrm{M}_{1}$
(b) risky debt
$\mathrm{M}_{1} \leq \mathrm{R} \mathrm{v}_{\mathrm{D}} \leq \mathrm{M}_{2}$
(c) "pseudo-debt"
$\mathrm{M}_{2}<\mathrm{R} v_{\mathrm{D}}$ 
The last case is one in which so much debt is issued that the firm goes bankrupt in each state of the world, and the return to equity is always zero. Debt has effectively replaced equity as the sole security in the economy and possesses the risk attributes of complete equity financing. Since interest payments are deductible against the corporate income tax, such an outcome has the attraction that no corporate tax is ever paid, and would appeal to institutions which are exempt from personal but not corporate taxes. Households, however, would not welcome such a financial policy for tax reasons unless 3

$$
\left(1-t_{p}\right)>\left(1-t_{c}\right)\left(1-t_{e}\right)
$$

If this inequality constraint is satisfied then in the absence of uncertainty both households and institutions could choose a debt-equity ratio sufficiently high to ensure that the profits of the firm were always distributed in the form of payments to bondholders. We describe this case as one of "pseudo-debt". This "super-regime" is degenerate in that it contains a single equilibrium described by

$$
\begin{aligned}
& v_{D}^{H}=w^{H}, \quad v_{D}^{I}=w^{I}, v_{D}=1 \\
& v_{E}^{H}=v_{E}^{I}=v_{E}=0 \\
& R \geq M_{2}
\end{aligned}
$$


Even if households prefer debt to equity for tax reasons, they may wish to move away from all-debt financing in order to be able to diversify into another security, namely equity. Only if the tax advantage from debt was sufficiently large would they be happy to forego the benefits of diversification. If condition (9) does not hold, then, considerations of both tax and portfolio diversification would lead households to prefer an interior solution for the debt-equity ratio. It is clear that households and institutions may disagree over whether or not pseudo-debt is a desirable regime, and the outcome will depend on which group has control of the firm. Each group will compare their expected utility level under the regime of pseudo-debt with the maximum levels attainable under the two other super-regimes. Expected utility of institution may be measured by the expected value of their consumption which, with pseudodebt, is

$$
E\left(c^{I}(\theta)\right)=w^{I}\left[(1-p) M_{1}+p M_{2}\right]
$$

We shall assume, henceforth, that households display constant relative risk aversion and the degree of relative risk aversion is unity, which implies that household utility may be written

$$
u^{H}\left(c^{H}\right)=\log C^{H}
$$

The expected utility level of households in the pseudo-debt case is

$$
E\left(u^{H}\right)=\log \left(1-t_{p}\right) w^{H}+(1-p) \log M_{1}+p \log M_{2}
$$


Further consideration of the probability of pseudo-debt occurring will be postponed until we have characterized the other regimes.

\section{Risky Debt}

\section{A. Characterization}

The intermediate "super-regime", that of risky debt is the major subject of focus in this paper. It is in many ways the most interesting case, and perhaps the most instructive about observed financial behavior. In this regime, the firm goes bankrupt in the first state of the world, and the returns to both debt and equity are risky. Because households are risk-averse, they will generally diversify and will always hold at least some debt. 4 Using (4), (5), (6) and (12), we write the expected utility which households seek to maximize as

$$
\begin{gathered}
E\left(u^{H}\right)=(1-p) \log \left[v_{D}^{H} \cdot \frac{M_{1}}{v_{D}}\left(1-t_{p}\right)\right]+p \log \left[\left(w-v_{D}^{H}\right)\left(\frac{M_{2}-R v_{D}}{v_{E}}\right)\left(1-t_{e}\right)\left(1-t_{c}\right)\right. \\
\left.+v_{D}^{H} R\left(1-t_{p}\right)\right]
\end{gathered}
$$

Through use of the accounting identities (1) and (2), the first-order condition for household expected utility maximization with respect to $v_{D}^{H}$ may be written ${ }^{5}$

$$
R=T M_{2} \cdot \frac{\left(v_{D}-v_{D}^{I}\right)-(1-p) w^{H}}{\left(1-v_{D}\right)\left(v_{D}-v_{D}^{I}\right)+T v_{D}\left[\left(v_{D}-v_{D}^{I}\right)-(1-p) w^{H}\right]}
$$

where

$$
T=\left(1-t_{c}\right)\left(1-t_{e}\right) /\left(1-t_{p}\right)
$$


may be viewed as the household's absolute "tax preference" for equity $(\operatorname{see}(9))$.

Note that, given $v_{D},(15)$ is an expression of one unknown variable, the interest rate $R$, in terms of another, the institutional holdings of bonds, $v_{D}^{I}$.

Unlike households, institutions are risky-neutral and will specialize in which ever asset yields a higher expected return. They will hold only debt if $E\left(r_{D}\right)>E\left(r_{E}\right)$, only equity if $E\left(r_{D}\right)<E\left(r_{E}\right)$, and diversify only if these expected returns are equal. Using (3), (4) and (5), we may summarize each of these three "sub-regimes" of the risky-debt "super-regime" by one equation and one inequality constraint in the unknown variables:

Regime 1: Institutions Specialize in Debt

$$
\begin{aligned}
& V_{D}^{I}=1-w^{H} \\
& R>R^{*}
\end{aligned}
$$

Regime 2: Institutions Specialize in Equity

$$
V_{D}^{I}=0
$$

$$
\mathrm{R}<\mathrm{R}^{*}
$$

Regime 3: Institutions Diversify

$$
\mathrm{R}=\mathrm{R}^{*}
$$

$$
1-w^{H} \geq v_{D}^{I} \geq 0
$$

where

$$
R^{*}=\frac{\left(1-t_{c}\right) M_{2}-\left(\frac{1-p}{p}\right)\left(\frac{1-v_{D}}{v_{D}}\right)_{M_{1}}}{1-t_{c} v_{D}}
$$


Under each regime, we have two equations, (15) and (16), in two unknown variables, $v_{D}^{I}$ and $R$, plus an inequality constraint, (17), in one of the two unknown variables.

There exists an equilibrium in a particular regime for a specific value of $v_{D}$ if a solution to the relevant system of equations satisfies the inequality constraint which applies. For an equilibrium with institutions specialized in debt, the value of $R$ obtained from (15) for $v_{D}^{I}=1-w^{H}$ must exceed $R^{*}$, which is not a function of $v_{D}^{I}$; for one in which institutions hold only equity, setting $v_{D}^{I}=0$ and solving (15) for $R$ must yield a value below $R^{*}$; for an equilibrium in which institutions hold both assets, there must exist a value of $v_{D}^{I}$ between its extreme values at which (15) yields a value of $R$ equal to $R^{*}$.

\section{B. Description of Equilibria}

Aside from the relevant inequality constraint (17), any solution must be one in which debt is risky; otherwise, the equations used to determine the equilibrium are inapplicable. By the definition stated above, debt is risky if and on if

$$
M_{1} \leq R v_{D} \leq M_{2}
$$

Thus, on a graph of $R$ versus $v_{D}$, in Figure 1, the feasible region for risky debt is the band between the two rectangular hyperbolas $\mathrm{Rv}_{\mathrm{D}}=\mathrm{M}_{1}$ (labeled $\left.m_{1}\right)$ and $R v_{D}=M_{2}\left(m_{2}\right)$. We may subdivide this region into feasible regions for each of the three risky-debt sub-regimes outlined above. Defining $R^{*}\left(v_{D}\right)$ from (18), Regime 1 is feasible if $R>R^{*}$, Regime 2 if $R<R^{*}$, and Regime 3 if $R=R^{*}$. Since 


$$
\frac{d R^{*}}{d v_{D}}=\left[\frac{\left(\frac{1-p}{p}\right) M_{1}}{v_{D}^{2}}+t_{c} R^{*}\right] /\left(1-t_{c} v_{D}\right)
$$

must be positive in the relevant range, and since $R^{*}=M_{2}$ at $v_{D}=1, R^{*}\left(v_{D}\right)$ can be represented by a curve such as the one labeled $R^{*}$ in Figure 1 and the areas feasible for Regimes 1, 2, and 3 are labeled I, II, and II, respectively.

To determine equilibria, we must consider the household portfolio balance condition (15). Define $\hat{R}\left(v_{D}, v_{D}^{I}\right)$ by the value of $R$ obtained from (15) for specific values of $v_{D}$ and $v_{D}$. For any value of $v_{D}^{I}$, it is only necessary to define $R$ over values of $v_{D}$ sufficiently large that $\left(v_{D}-v_{D}^{I}\right)$ exceeds $(1-p) w^{H}$, so that both numerator and denominator of the term in (15) are positive. ${ }^{6}$ Let $\hat{R}^{1}\left(v_{D}\right)=\hat{R}\left(v_{D}, 1-w^{H}\right)$ and $\hat{R}^{2}\left(v_{D}\right)=\hat{R}\left(v_{D}, 0\right)$ be the relevant functions for Regimes 1 and 2, respectively. Any candidate $\left(R, v_{D}\right)$ for an equilibrium in which institutions specialize in debt must reside in Sector $I$ in Figure 1 and satisfy $R=\hat{R}^{1}\left(v_{D}\right)$. Similarly, if a point is to be an equilibrium with institutions holding just equity, $\left(R, v_{D}\right)$ must fall in Sector II and $R$ must equal $\hat{R}^{2}\left(v_{D}\right)$. An equilibrium of the third type must satisfy $R^{*}=\hat{R}\left(v_{D}, v_{D}^{I}\right)$ for some intermediate value of $v_{D}$. The behavior of the function $\hat{R}$ will determine the pattern of equilibria; the following collection of results is proved in the appendix.

\section{Proposition 1:}

(i) $\frac{\partial R}{\partial v_{D}^{I}}<0$ for $v_{D}<1$

$$
\hat{\mathrm{R}} \equiv \mathrm{M}_{2} \text { for } \quad \mathrm{v}_{\mathrm{D}}=1
$$


(iii) For any given $v_{D}^{I}$, over the relevant range of $v_{D}, \hat{R}$ is either strictly increasing, strictly decreasing, or increasing and then decreasing. In particular, if $\mathrm{pT}<1, \hat{\mathrm{R}}^{1}$ is strictly increasing.

Part (i) of the proposition merely states that the interest rate must increase to induce households to wish to hold more debt. In conjunction with the second part, this says that $R$ pivots up around the point $\left(1, M_{2}\right)$ in $\left(v_{D}, R\right)$ space as $v_{D}^{I}$ declines. Part (jii) says that the lowest of these curves, $R$, is positively sloped throughout as long as $\mathrm{pT}<1$, a condition which is hard to interpret but is likely to be satisfied unless the favorable outcome is almost certain, since $T$ is unlikely to be much greater then unity.

Now, consider the function $R^{m}\left(v_{D}\right)$ which chooses the median value from among $\hat{R}^{1}\left(v_{D}\right), \hat{R}^{2}\left(v_{D}\right)$ and $R^{*}\left(v_{D}\right){ }^{7}$ This function traces out all risky debt equilibria, as is now shown.

\section{$\underline{\text { Proposition } 2}$}

(i) A pair $\left(v_{D}, R\right)$ is a risky-debt equilibrium if and only if condition (19) is satisfied and $R=R^{m}\left(v_{D}\right)$;

(ii) If $\mathrm{pT}<1$, the locus of such points is a continuous segment along which $R$ is increasing with respect to $v_{D}$.

\section{proof:}

(i) It is clear that any solution must satisfy (19). It remains to be shown that if this condition is met, there exists a unique equilibrium, given $v_{D}$, at $R=R^{m}\left(v_{D}\right)$. The proof is by cases. 
a. $\mathrm{R}^{*} \leq \hat{R}^{1}<\hat{R}^{2}$. Equations (15) and (16.1) and inequality constraint (17.1) are satisfied by $v_{D}^{I}=1-w^{H}$ and $R=\hat{R}^{1}$, so that a "Regime l" equilibrium exists at $R=\hat{R}^{1}=R^{m}$. By Proposition 1 , any other value of $\hat{R}$ exceeds $\hat{R}$, so that neither (16.2) and (17.2) nor (16.3) and (17.3) can hold simultaneously.

b. $\hat{\mathrm{R}}^{1}<\mathrm{R}^{2} \leq \mathrm{R}^{*}$. It follows in an analogous manner that there exists a unique equilibrium of $R=R^{2}=R^{m}$.

c. $\hat{\mathrm{R}}^{1}<\mathrm{R}^{*}<\hat{\mathrm{R}}^{2}$. It is evident that neither (16.1) and (17.1) nor (16.2) and (17.2) can hold simultaneously, so that the only candidate for equilibrium is Regime 3 . Since $\hat{R}$ is continuous $\hat{R}=R^{*}$ for some value of $v_{D}$ between 0 and $\left(1-w^{H}\right)$, so that (16.3) and (17.3) are satisfied and $R=R^{*}=R^{m}$.

Since these cases are exhausted, the proof of part (i) is complete.

(ii) Since $R^{*}, \hat{R}^{1}$ and $\hat{R}^{2}$ are all continuous, so is $R^{m}$. What we must rule out is that $R^{m}$ passes out of and then back into the region defined by condition (19). We can certainly do so once we show that $R^{m}$ increases monotonically with respect to $v_{D}$.

Since $\frac{\partial R^{*}}{\partial v_{D}}>0$ and, for $\mathrm{pT}>1, \frac{\partial \hat{R}^{1}}{\partial v_{D}}>0, R^{m}$ will also be increasing with respect to zero unless $R^{m}=R^{2}$ at a point where $\frac{\partial R^{2}}{\partial v_{D}}<0$. But this can't happen. Were this so, then, by Proposition $1, \hat{R}^{2}$ would 
continue to decline until equalling $M_{2}$ at $v_{D}=1$. Since $\frac{\partial R^{*}}{\partial v_{D}}>0$ and $R^{*}$ also equals $M_{2}$ at $v_{D}=1$, this would imply that $\mathrm{R}^{*}<\hat{\mathrm{R}}^{2}$ at the current $v_{D}$, implying that $\mathrm{R}^{\mathrm{m}} \neq \hat{\mathrm{R}}^{2}$. Thus, $\mathrm{R}^{\mathrm{m}}$ can equal $\hat{R}^{2}$ only if, at that point, $\frac{\partial R^{2}}{\partial v_{D}}>0$, which ensures the monotonicty of $\mathrm{R}^{\mathrm{m}}$.

Typical representations of $\hat{R}^{1}$ and $\hat{R}^{2}$ are shown in Figure 2 , along with the curves $m_{1}, m_{2}$ and $R^{*}$. The equilibria along $R^{m}$ are shaded.

Two additional comments are in order about the shapes of these curves. First, although we shall, henceforth, assume it to be satisfied, the condition that $\mathrm{pT}<1$, although not very constraining, is not very crucial, either. If PT were greater than one, this would merely cause the equilibrium curve $R^{m}$ to peak at a value of $v_{D}<1$. The only complication that could occur might be that for $\mathrm{pT}^{\mathrm{T}}$ implausibly large, $\mathrm{R}^{\mathrm{m}}$ might intersect $\mathrm{m}_{1}$ in more than one place. The second point concerns the shapes of the curves $\hat{R}_{1}, \hat{R}_{2}$ and $R^{*}$. As we have drawn them in Figure $2, \hat{R}^{1}$ and $\hat{R}^{2}$ intersect $R^{*}$ in at most one place other than at $v_{D}=1$; were $\hat{R}^{1}$ and $\hat{R}^{2}$ concave downward, and $R^{*}$ concave upward, we could prove that each of $\hat{R}^{1}$ and $\hat{R}^{2}$ could intersect $R^{*}$ at most once, and that at such intersections $R^{*}$ would be the flatter of the two curves. We are not quite able to do this; however, numerous empirical simulations indicate that the curves will behave in this way for any conceivable parameter values, and that the regimes of equilibria occur in the order shown in Figurb 2. To be more specific, suppose $v_{D}^{m}$ is the value of $v_{D}$ at which $R^{m}$ intersects $m_{1}$. Then there will exist values $v_{D}^{1}$ and $v_{D}^{2}$, such that $v_{D}^{m} \leq v_{D}^{1}<v_{D}^{2} \leq 1$ and, for each value of $v_{D}$ between $v_{D}^{m}$ and 1 , there will be a risky-debt equilibrium in which institutions

(i) specialize in equity if $v_{D}^{m}<v_{D} \leq v_{D}^{I}$ 
(ii) diversify if $\quad v_{D}^{1}<v_{D}<v_{D}^{2}$

(iii) specialize in debt if $v_{D}^{2} \leq v_{D}<1$

This result is in accordance with intuition and we sha11 assume it to be valid in the following discussion. When debt is not very risky, institutions hold none or 1ittle of it, even given their relative tax preference for it, because they can obtain a higher return on the risky equity which households do not wish to hold. As the leverage of the firm increases, debt gets riskier, and households are less willing to hold it. This drives down the return on equity relative to debt, and institutions shift into debt. What is somewhat surprising is that, through all of the ownership shifts occurring as $v_{D}$ rises, the interest rate $R$ is a stable, monotonic function of $v_{D}$.

\section{Effects of Changes in Risk or Tax Rates}

The equilibrium framework we have presented in this section lends itself quite naturally to the study of the effects of parameter changes on the system. By assessing the impact of these changes on the functions $\hat{R}^{1}, \hat{R}^{2}$ and $R^{*}$, we may depict these effects graphically. We consider first the effects of changing the corporate tax rate, $t_{c}$, the household tax on interest, $t_{p}$, and the household tax on equity, $t_{e}$. In all cases, we consider an uncompensated change in the tax. 8

\section{(i) Tax Rate Changes}

The effects of changes in $t_{c}, t_{e}$ and $t_{p}$ on $\hat{R}^{1}$ and $\hat{R}^{2}$ are found by differentiating $\hat{R}$ with respect to the particular tax rate, for $v_{D}^{I}=1-w^{H}$ and $v_{D}^{I}=0$, respectively. Since the numerator and denominator of (15) are both positive at equilibrium values (see footnote 6), it is clear that 
$\frac{\partial R}{\partial T}>0$ for all values of $v_{D}^{I}$, specifically 0 and $\left(1-w^{H}\right)$. Thus, any increase in $T$ shifts $\hat{R}^{1}$ and $\hat{R}^{2}$ upward; such an increase will occur if $t_{p}$ increases or $t_{c}$ or $t_{e}$ decreases. $R^{*}$ is not a function of either $t_{e}$ or $t_{p}$. Thus, an increase in $t_{p}$, or a decrease in $t_{e}$ will have the effect shown in Figure $3 a$. The rate of interest at each point will either increase or remain constant, the range of values of $v_{D}$ over which institutions specialize in debt (Regime 1) increases, and the range of values of $v_{D}$ over which institutions specialize in equity declines. To summarize these results, a tax change which increases the household's tax preference for equity without affecting that of institutions (which depends only on $t_{c}$ ) will increase the likelihood that institutions hold only debt or at least some debt and will increase the coupon rate in some cases, having no effect in others.

This shift of institutions toward debt need not occur from a change in $t_{c}$, since the tax preference of institutions, as well as that of households, is affected. As shown in the preceding paragraph, a rise in $T$, which could result from a decrease in the corporate tax rate, raises $\hat{R}^{1}$ and $\hat{R}^{2}$. However, we can see from (18) that $R^{*}$ also depends on $t_{c}$. A simple calculation shows that $\frac{d R^{*}}{d t_{c}}<0$, so that a decline in $t_{c}$ also raises $R^{*}$. Thus, the effect of a decrease in $t_{c}$, shown in Figure $3 b$, is certain to raise $R$ at any given $v_{D}$, but the effect on regime is uncertain. 
(ii) Changes in Risk

We must first define what we mean by "risk". We choose to consider an increase in risk to be any change in the parameters $M_{1}$, $M_{2}$, and $p$ which keeps the mean return to the firm

$$
\mu=\mathrm{pM}_{2}+(1-\mathrm{p}) \mathrm{M}_{1}
$$

constant, but increases the variance of this return, 8

$$
\begin{aligned}
\sigma^{2} & =\left(M_{2}-M_{1}\right)^{2} p(1-p) \\
& =\left(M_{2}-\mu\right)\left(\mu-M_{1}\right)
\end{aligned}
$$

Thus, an increase in variance with mean constant can occur from an increase in $M_{2}$, a decrease in $M_{1}$, or both. We consider each of these cases.

(a) $M_{1}$ decreases, $M_{2}$ fixed ("Catastrophe Risk")

From (20), it is clear that a decrease in $\mathrm{M}^{1}$ with mean constant and $M_{2}$ fixed implies an increase in $p$. The chance of the bad state occurring is lower but its outcome is more ruinous. We wish to calculate the changes in $\hat{R}^{1}, \hat{R}^{2}$ and $R^{*}$. $\hat{R}$ is not a function $M_{1}$ directly, but does depend on $p$. The partial derivative of $R$ with respect to $p$ is:

$$
\frac{\partial \hat{R}}{\partial p}=\frac{T M_{2} w^{H}}{D^{2}}\left(1-v_{D}\right)\left(v_{D}-v_{D}^{I}\right)
$$

where $\mathrm{D}$ is the denominator in (15). 
Since $v_{D}-v_{D}^{I}>0, \frac{\partial \hat{R}}{\partial p}$ is positive and, since $\left.\frac{d p}{d M_{1}}\right|_{\mu}$ is positive, $\frac{d \hat{R}_{1}}{d M_{1}}>0$. Thus, curves $\hat{R}^{1}$ and $\hat{R}_{2}$ both shift up. Combining (20) and (18), we obtain:

$$
R^{*}=\frac{M_{2}\left[\left(1-t_{c}\right)+\left(\frac{1-v_{D}}{v_{D}}\right)\right]-\left(\frac{1-v_{D}}{v_{D}}\right) \frac{\mu}{p}}{1-t_{c} v_{D}}
$$

so that this change in $M_{1}$ and $p$ holding $\mu$ constant clearly increases $R^{*}$.

Thus, all three curves shift up. Like a decrease in the corporate tax rate, an increase in "catastrophe risk" increases the rate of interest for all risky-debt equilibria, but has an uncertain impact of the determination of regime. Unlike the previous case, the increase in $R$ occurs because the expected return to debt, given $R$, decreases as $M_{1}$ decreases, due to limited liability.

(b) $M_{1}$ decreases, $M_{2}$ increases ("dispersion risk")

For simplicity, we consider relative changes in $M_{1}$ and $M_{2}$ which keep p constant.

It is clear that such an increase in risk increases $\hat{R}$, since $\hat{R}$ depends positively on $M_{2}$ and is independent of $M_{1}$. From (23), it also follows, that an increase in $M_{2}$ with $p$ and $\mu$ fixed increases $R^{*}$. Thus, as in the previous case, a11 three curves shift up, raising the interest rate at all risky-debt equilibria but having an uncertain effect on regime. 
(c) $M_{1}$ fixed, $M_{2}$ increases ("Sweepstakes risk")

Such an increase in risk must, for $\mu$ constant, be accompanied by a decrease in $p$. Thus, we may think of this increase in risk as a combination of an increase in $M_{2}$ and a decrease in $M_{1}$ with an increase in $M_{1}$ of equal size and a decrease in $\mathrm{p}$ - an increase in "dispersion risk" coupled with a decrease in "catastrophe risk". Since these two types of risk have similar effects on $\hat{R}^{1}, \hat{R}^{2}$ and $\hat{R}^{m}$, this combination might be expected to have an uncertain total impact. Indeed, this hypothesis is borne out by an examination of the relevant derivatives, which indicate that the effects on $\hat{R}^{1}$, $\hat{R}^{2}$ and $R^{*}$ are all uncertain.

The key to understanding why an increase in this type of risk has a different effect on equilibrium values of $R$ lies in the fact that $M_{1}$ declines in cases (a) and (b), but not here. For $\mathrm{R}$ constant, a decrease in $\mathrm{M}_{1}$ diminishes the actual return to debt in the bad state, $M_{1} / v_{D}$, but has no effect on that in the good state. Thus, the expected return to holding debt decreases, and $R$ must increase to compensate for this. This is not a risk premium, but merely an increased difference between the coupon rate and the actual expected return to holding debt. Since $\mathrm{M}_{1}$ does not decline with an increase in "sweepstakes risk", no such effect is present. 


\section{A Note on Household Non-Negativity Constraints}

As already shown above, any condition constraining households from engaging in short sales of debt will never be binding when debt is risky. The remaining issue concerns potential short sales of equity. Such a constraint would be binding if, at an equilibrium, total equity, $v_{E}$, were less than that held by institutions, or, using the accounting identities,

$$
w^{H}<v_{D}-v_{D}^{I}
$$

It is evident from (24) that the possibility of household short sales diminishes as the fraction of wealth held by household increases. Nevertheless, it might appear that for large values of $v_{D}$ near one, such sales would be inevitable. But here the pattern of equilibria described above becomes relevant. Since institutions go from holding equity to holding debt as $v_{D}$ increases, the right-hand side of (24) rises less rapidly than $v_{D}$ rises. Thus, short sales need not occur at all, and the constraint may become superfluous.

Although our model could be adapted to account for a constraint on household short sales of equity, our simulations indicate that short sales are unlikely to arise even without a constraint and, hence, we do not attempt such an exercise.

\section{Riskless Debt}

The final regime we consider is that in which there is insufficient debt issued for bankruptcy to be possible; debt's rate of return is certain and equal to the coupon rate. The expected utility of households is 


$$
\begin{aligned}
E\left(u^{H}\right) & =(1-p) \log \left[v_{D}^{H} R\left(1-t_{p}\right)+\left(w^{H}-v_{D}^{H}\right) r_{e}(1)\left(1-t_{e}\right)\right] \\
& +p \log \left[v_{D}^{H} R\left(1-t_{p}\right)+\left(w^{H}-v_{D}^{H}\right) r_{e}(2)\left(1-t_{e}\right)\right]
\end{aligned}
$$

The derivative of expected utility with respect to $v_{D}^{H}$ may be rearranged to yield:

$$
C_{1}^{H_{2}} C_{2}^{H} \frac{d E^{\left(u^{H}\right)}}{d v_{D}^{H}}=C_{1}^{H}\left[\left(1-t_{p}\right) R-(1-t) E\left(r_{e}\right)\right]+(1-p)\left(C_{2}^{H}-C_{1}^{H}\right)\left[\left(1-t_{p}\right) R-\left(1-t_{e}\right) r_{e}(1)\right]
$$

from which a couple of things may be observed. If the after-tax expected returns to equity and debt are equal, households will choose to hold only debt, an outcome one would certainly expect in a model such as this. This may be seen by noting that in such a case, the first term on the right-hand side of (25) is zero, and the second has the same sign as $\left(\mathrm{C}_{2}^{\mathrm{H}}-\mathrm{C}_{1}^{\mathrm{H}}\right)$. Since $\mathrm{C}_{2}^{\mathrm{H}}>\mathrm{C}_{1}^{\mathrm{H}}$ when $\mathrm{v}_{\mathrm{D}}^{\mathrm{H}}<{ }^{\mathrm{H}}$ and $\mathrm{C}_{2}^{\mathrm{H}^{*}}<\mathrm{C}_{1}^{\mathrm{H}}$ when $\mathrm{v}_{\mathrm{D}}^{\mathrm{H}}>\mathrm{w}^{\mathrm{H}}$, it follows that expected utility is maximized when $v_{D}^{H}=w^{H}$, and $v_{E}^{H}=0$.

Since $t_{p}>t_{e}$, a case in which households have the same expected return on debt and equity would correspond to one in which institutions would receive a higher return on debt. No one would hold equity, and this possibility can be dismissed since $v_{D}<1$. Thus, the expected return on equity $E\left(r_{e}\right)$ must exceed $\left(1-t_{p}\right) R /\left(1-t_{e}\right)$.

Beyond this, there are few limiations on the pattern of portfolio holdings. It is possible to envision situations in which institutions specialize in debt, equity or are diversified while households are either diversified or hold only equity. The outcome will depend, in general, on two factors. First, the greater is the inherent risk of the firm, the more reluctant households will be to move into equity as its rate of return rises. 
In a situation with the firm very risky, therefore, we would expect to see households diversified, with institutions absorbing increases or decreases in the supply of securities. At the other extreme, were $M_{2} \approx M_{1}$, households would shift their entire portfolio into equity as soon as the return to equity rose slightly above $\left(1-t_{p}\right) R /\left(1-t_{e}\right)$, but before it rose to $R$, leaving institutions specialized in debt. This behavior corresponds to that occurring in the absence of risk, not surprisingly. The second factor influencing the pattern of holdings is the distribution of wealth between households and institutions. Here, the fairly obvious point is that if institutions hold only a small fraction of the wealth, it is unlikely we will observe an equilibrium in which households specialize in equity, for someone must hold the existing debt.

Unfortunately, we are unable to produce for this regime the kind of simple analytical results obtained in the previous case without imposing more restrictive assumptions.

VI. Simulation Results

To illustrate the results developed above for the cases of risky debt and "pseudo-debt", we present two simulations of our model. In the first simulation, we take the probability of success, $p$, to be .75 , and the returns to the firm in the two states, $M_{1}$ and $M_{2}$, to be 1 and 6 , respectively. Household wealth $w^{H}$ is set at .75 . We set the corporate $t_{a x} t_{c}$, equal to .4 , and initially set the rates of personal taxation, $t_{p}$ and $t_{e}$, equal to .4 and 0 , respectively. The results, listed in Table 1 , show the security holdings of households and institutions, the expected returns to equity and debt, the expected utility of households, and the coupon rate on bonds. 
The resulting equilibria follow the pattern shown in Figure 2. Debt is risky as long as $v_{D} \geq .33$, with institutions holding only equity for $v_{D}<.36$, diversified for $.36 \leq v_{D} .66$, and holding only debt for all higher values of $v_{D}$. Households are diversified throughout, and hold the majority of their wealth in equity for values of $v_{D}$ below .44 .

The results concerning the expected returns on securities and expected utility of households are quite interesting. While the expected return on debt increases steadily as debt gets riskier, the expected return on equity does not, increasing with $v_{D}$ to the point at which institutions shift entirely out of equity, and decreasing thereafter. Household expected utility is not only nonmonotonic, but it has multiple peaks, one at the point where institutions shift out of equity, and the global maximum at the point where debt is least risky.

These results highlight an important issue alluded to in the introduction. Because of different attitudes toward risk and different tax schedules, households and institutions may differ as to what the "optimal" debt-equity ratio is. In this example, restricted to the case where debt is not perfectly safe, households would prefer the smallest leverage possible, while institutions would prefer the greatest - "pseudo-debt". Since households are always the majority stockholders, they can dictate the choice of $v_{D}$. However, one could imagine a situation arising in which each group's "optimal" debtequity ratio occurred at a point at which the other was in control of the firm. In such a situation, the choice of a debt-equity ratio "in the interests of the stockholders" would be difficult indeed! 
The second simulation illustrates another issue raised in the introduction. Here we increase both personal income taxes, setting $t_{p}=.549$ and $t_{e}=.25$, leaving all other parameters the same as in the first simulation. The results are shown in Table 2. An important point which we wish to illustrate here is that even though both institutions and households have a tax preference for debt $(T=.998)$ they do not agree that a "pseudo-debt" equilibrium is optimal. The gains from diversification made available as more equity is issued outweigh any tax disadvantages that households suffer. In fact, households again prefer the debt-equity ratio at which debt is least risky. As concerns the incidence of these tax increases, household utility is reduced to less than half of its original level at all values of $v_{D}$ as a result of the increases in personal income tax rates. However, there is only a minor effect on the rate of return earned by institutions. In fact, at the debt-equity ratio which would be optimal from the households' viewpoint, $v_{D}=.33$, the expected return of institutions, who hold only equity, actually increases.

\section{Conclusions}

In this paper, we have presented a very simple general equilibrium model of the portfolio behavior of households and institutions, paying particular attention to the influence of differences in tax rates and attitudes toward risk. Despite the restrictive nature of our model, it yields very complex results, only some of which have been explored in the foregoing analysis. A number of extensions might be suggested. First, greater attention should be given to determining the pattern of holdings which arises when debt is riskless. Second, an important policy issue is the general equilibrium effect of tax changes on the welfare of different individuals. While we have examined the influence of separate, uncompensated tax changes on the model's 
outcome, our results concerning incidence, though interesting, must be considered merely illustrative. What is needed is the imposition of a government budget constraint, through which the effect of shifting the burden of assessment among different taxes could be evaluated.

Another issue we have not adequately addressed here is the determination of a firm's debt-equity ratio. As was illustrated in the numerical simulations, different classes of shareholders may consider radically different debt-equity ratios to be "optimal"; a majority voting rule need not result in a stable equilibrium, for the distribution of share ownership itself depends on the financial policy chosen by the firm.

A few words are also in order concerning the importance of some of our more restrictive assumptions. We have ruled out the existence of a safe asset unconnected with the firm, such as government bonds. If there were such an asset, there would then be three assets in the model. Since there are only two states of the world, only two of these assets are necessary to span the opportunity set and no investor will, in general, hold all three assets; we cannot tell which of the three an investor will hold, but two will be adequate. Consequently, we would lose the diversification of portfolios. This would be restored in moving to a model with three states of the world, with households holding all three assets, but such a model would be considerably more complex without affording a new dimension of insight. Replacing our one-firm model with one having several small firms would also cause a proliferation of securities, and each investor could specialize in the appropriate investment for tax purposes. Firms would specialize in stockholders, and we would once again lose diversification, which would reappear if the number of states of the world exceeded the number of firms. It is this phenomenon we wish to model. 
Finally, we recognize that the assumption that institutions are riskneutral is not entirely appropriate. If institutions were mildly riskaverse, it is hard to see how the qualitative nature of the results would be seriously changed, although this would add great complexity to the analysis. 
Appendix

In this section, we present demonstrations of the various results listed in Proposition 1 in the paper. For convenience, we restate each claim before giving its proof.

$$
\frac{\partial \hat{R}}{\partial v_{D}^{I}}<0 \text { for } v_{D}<1
$$

proof: Differentiating $\hat{R}$ as defined in (15) with respect to $v_{D}^{I}$ yields:

$$
\frac{\partial \hat{R}}{\partial v_{D}^{I}}=-\frac{T_{2}(1-p) w^{H}}{D^{2}} \cdot\left(1-v_{D}\right)
$$

where $D=\left(1-v_{D}\right)\left(v_{D}-v_{D}^{I}\right)+T v_{D}\left[\left(v_{D}-v_{D}^{I}\right)-(1-p) w^{H}\right]$.

$$
\hat{\mathrm{R}} \equiv \mathrm{M}_{2} \text { for } \quad \mathrm{v}_{\mathrm{D}}=1
$$

proof: At $v_{D}=1$,

$$
\hat{R}=\mathrm{TM}_{2} \cdot \frac{\left(1-v_{D}\right)-(1-p) w^{H}}{T\left[\left(1-v_{D}\right)-(1-p) w^{H}\right]}=\frac{T M_{2}}{T}=M_{2}
$$

(iii) For any given $v_{D}^{I}$, over the relevant range of $v_{D}, \hat{R}$ is either strictly increasing, strictly decreasing, or increasing and then decreasing. In particular, if $\mathrm{pT}<1, \hat{\mathrm{R}}^{1}$ is strictly increasing.

proof: Differentiating $\hat{R}$ with respect to $v_{D}$ yields

$$
\frac{\partial \hat{R}}{\partial v_{D}}=\frac{T M_{2}}{D^{2}}\left\{D-N\left[\left(1-v_{D}\right)-\left(v_{D}-v_{D}^{I}\right)+T\left(v_{D}-v_{D}^{I}-(1-p) w^{H}\right)+v_{D} T\right]\right\}
$$


where $D$ is as defined above and $N=\left(v_{D}-v_{D}^{I}\right)-(1-p) w^{H}$. Substituting into this expression the expressions for $N$ and $D$, and rearranging terms, we find that $\frac{\partial \hat{R}}{\partial v_{D}}>0$ if and only if:

$$
\phi=\frac{v_{D}-v_{D}^{I}}{v_{D}-v_{D}^{I}-(1-p) w^{H}}+\frac{(1-p) w^{H}\left(1-v_{D}\right)}{\left(v_{D}-v_{D}^{I}-(1-p) w^{H}\right)^{2}}-T>0 .
$$

Differentiating $\phi$ with respect to $\mathrm{r}_{\mathrm{D}}$ yields:

$$
\frac{\partial \phi}{\partial v_{D}}=-\frac{2(1-p) w^{H}}{D^{2}}\left(1+\frac{1-v_{D}}{D}\right)
$$

which is negative. Thus, $\phi$, and, hence, $\frac{\partial \hat{R}}{\partial v_{D}}$, will be always positive, always negative, or positive for $v_{D}$ smaller than some value and negative above it. This proves the first part of the above assertion. To prove the second part, we need only prove that $\frac{\partial \hat{R}}{\partial v_{D}}>0$ at $v_{D}=1$, since it must then be positive for smaller values of $v_{D}$. Evaluating $\frac{\partial R}{\partial v_{D}}$ at $v_{D}=1$ yields

$$
\left.\frac{\partial \hat{R}}{\partial v_{D}}\right|_{v_{D}=1}=\frac{T M_{2}}{D}\left[-\frac{(T-1)}{D}\left(1-v_{D}^{I}\right)+(1-p) w^{H}\right]
$$

which is positive if and only if

$$
(1-p) w^{H}>\frac{T-1}{T}\left(1-v_{D}^{I}\right)
$$

which, for $v_{D}^{I}=1-w^{H}$, reduces to the condition

$$
\text { pT }<1
$$


Footnotes

1) Two examples of this type of result, arising from somewhat different theoretical assumptions, may be found in Miller (1977) and Auerbach (1979).

2) See Sharpe (1964) or Lintner (1965) for a treatment of this approach.

3) This condition is derived in King (1977), chapter 4.

4) This last result follows from the fact that equity has a zero return in state 1 and utility is logarithmic.

5) This assumes either that there are no short sale restrictions on households or that such restrictions as may exist are not binding at the optimum. It is clear from the previous footnote that the only restriction which might be relevant is one prohibiting short sales of equity. We shall return to this issue once this regime has been more fully explored.

6) No lower value of $v_{D}$ could be sustained as a risky-debt equilibrium. Since households always demand some debt $v_{D}^{H}=v_{D}-v_{D}^{I}>0$. It follows that if the numerator in (15) were negative, either the denominator would be positive and $\hat{R}<0$, or else the denominator would be negative and $\hat{R} v_{D}>M_{2}$; in either case, an equilibrium could not occur.

7) If one of these three values is not defined, choose the lower value of the two which are. It will never be necessary to define $\mathrm{R}^{\mathrm{m}}$ in situations where more than one of $R^{m}, \hat{R}^{1}$ and $\hat{R}^{2}$ are not defined.

8) It would be useful to know the compensated effects of such changes, as we11. However, this would be considerably more difficult to ascertain analytically and will not be attempted in this paper.

9) Since the returns $M_{1}$ and $M_{2}$ are certainly not normally distributed, the variance alone is not a perfect measure of "risk". Such a measure would need to take account of higher moments of the distribution of returns as we11, but in a complicated way. 


\section{$\underline{\text { References }}$}

Auerbach, A.J., 1979, "Wealth Maximization and the Cost of Capital," Quarterly Journal of Economics, forthcoming.

King, M.A., 1977, Public Policy and the Corporation (Chapman and Hall: London) .

Lintner, J., 1965, "The Valuation of Risk Assets and the Selection of Risky Investments in Stock Portfolios and Capital Budgets," Review of Economics and Statistics, February, 13-37.

Miller, M.R., 1977, "Debt and Taxes," Journal of Finance, May; 261-275.

Modigliani, F. and M.R. Miller, 1958, "The Cost of Capital, Corporation Finance, and the Theory of Investment," American Economic Review, June ; 261-297.

Sharpe, W., 1964, "Capital Asset Prices: A Theory of Market Equilibrium Under Conditions of Risk," Journal of Finance, September; pp. 425-442. 
Figure 1

Financial Policy Regimes

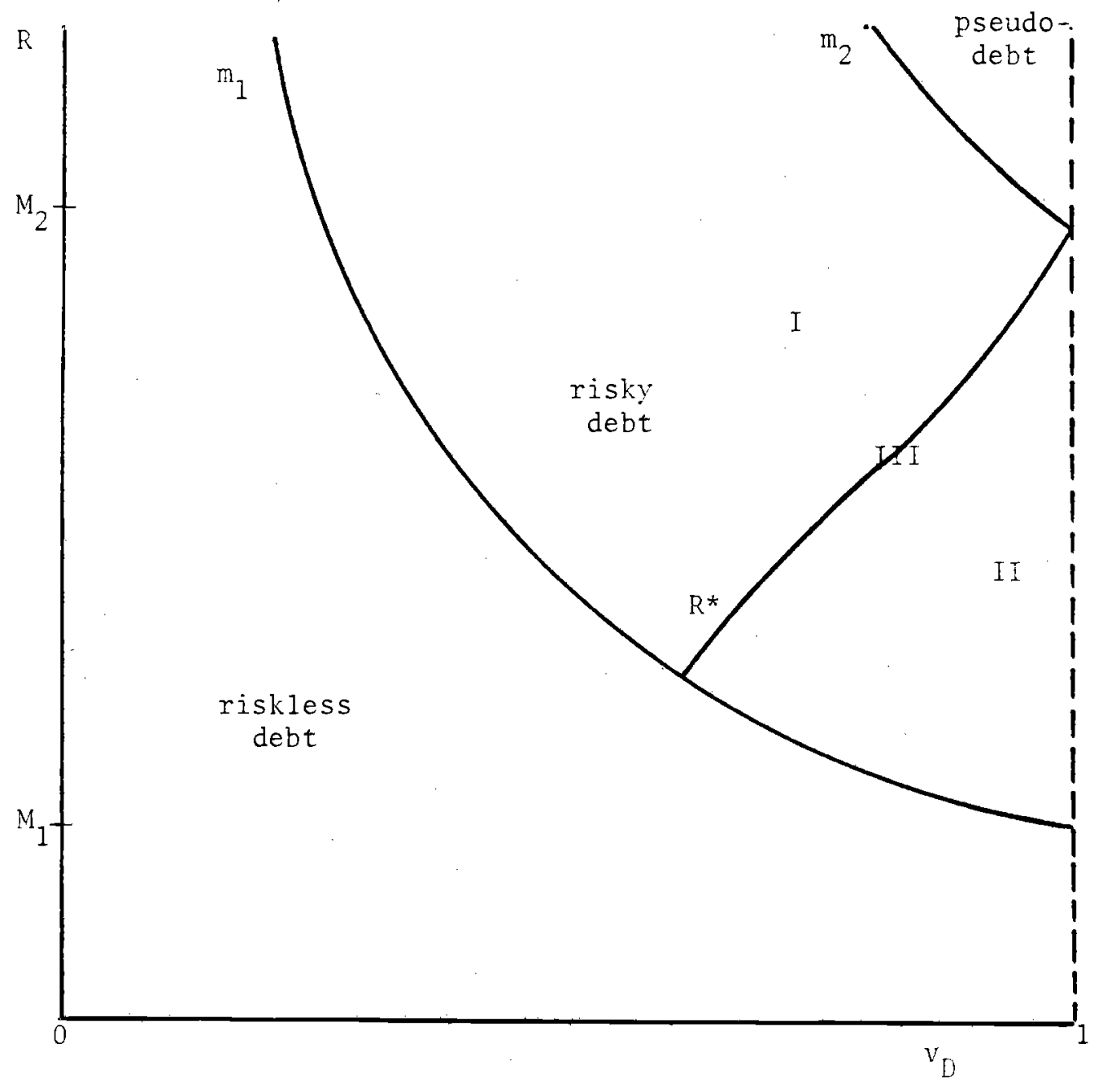


Figure 2

Risky-Debt Equilibria

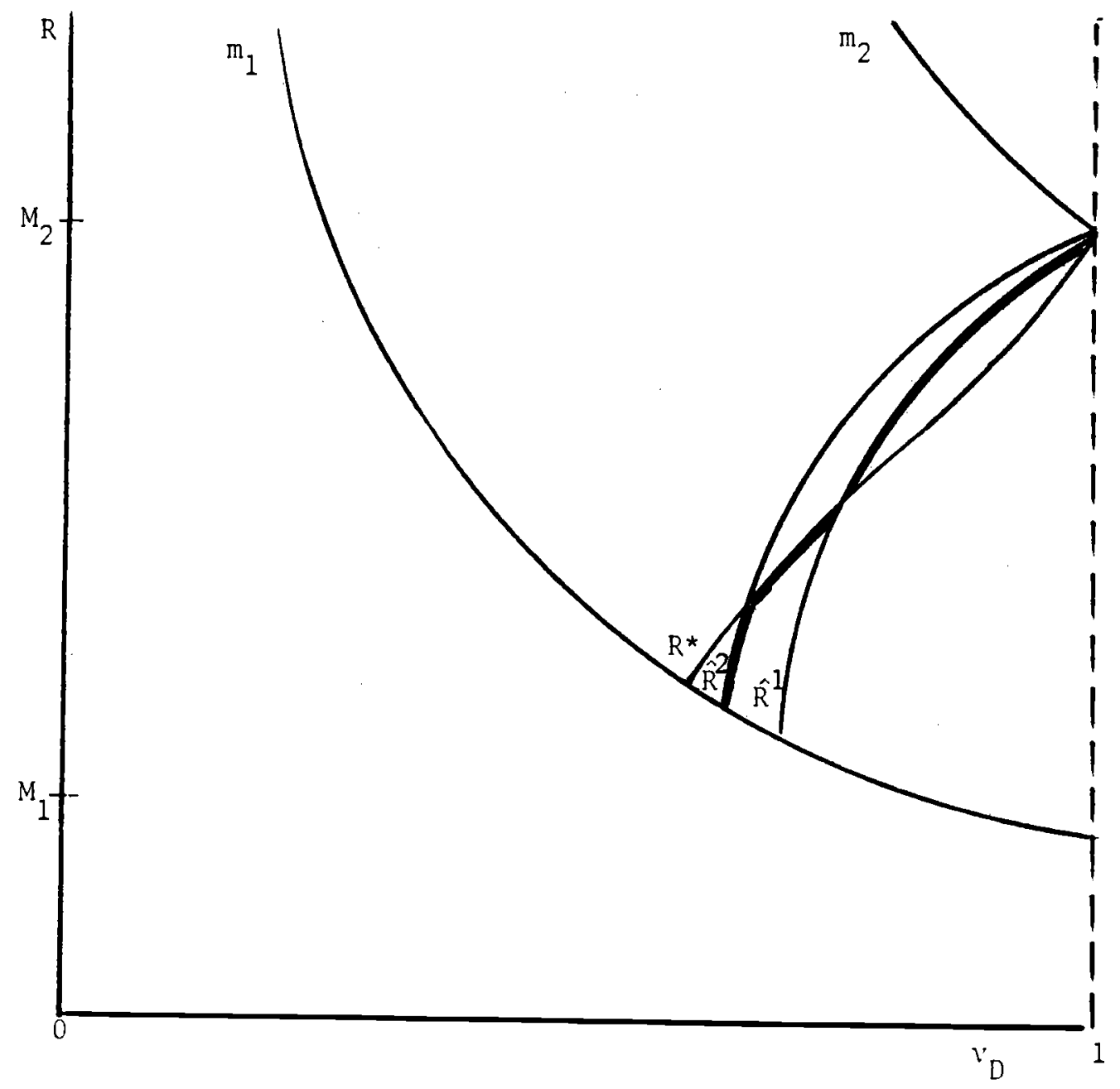


Figure 3

Tax Change Effects
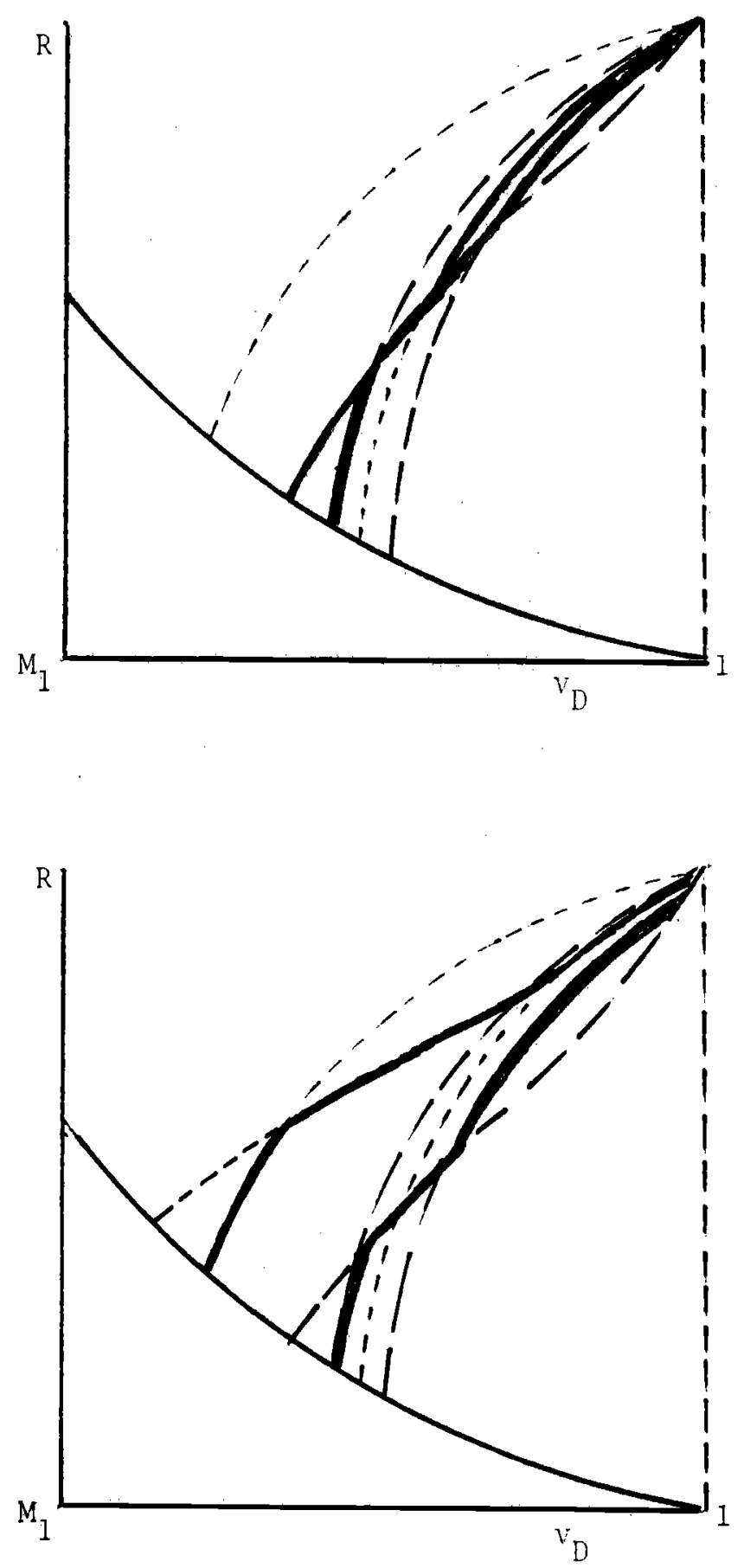

a. Increase in $t_{p}$

or

Decrease in $t_{e}$

$\left(\hat{R}^{1}, \hat{R}^{2}\right.$ shift up) b. Decrease in $t_{c}$ (All curves shift up) 
0.00000000000000000000000000000000

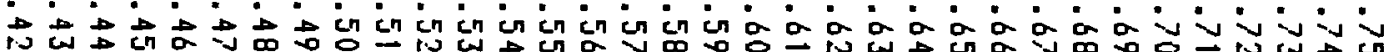

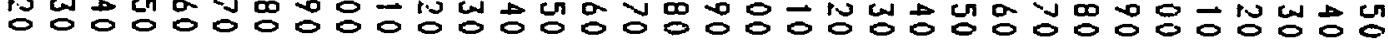
0000000000000000000000000000000000

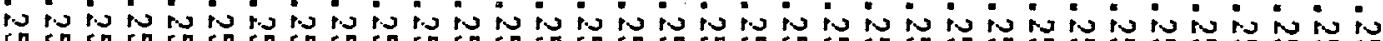

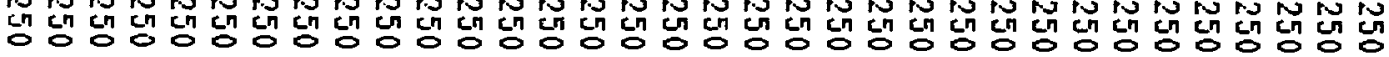
0000000000000000000000000000000001 a a

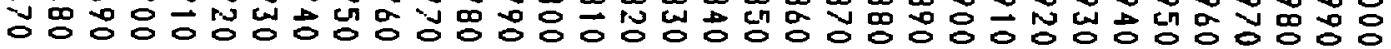

0000000000000000000000000000000000

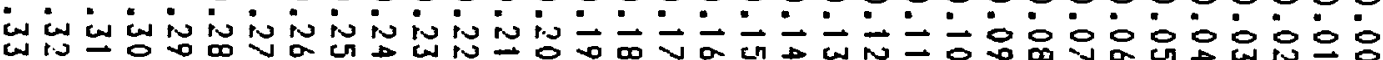
出 0000000000000000000000000000000000

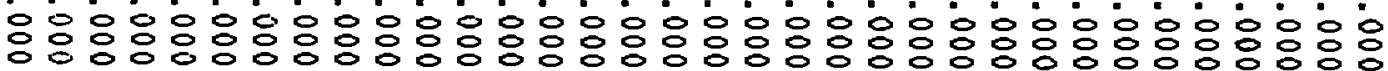

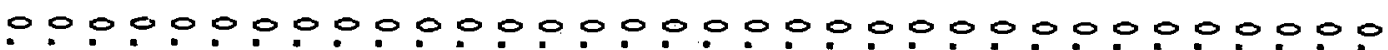

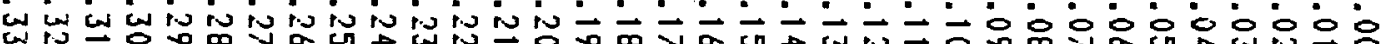

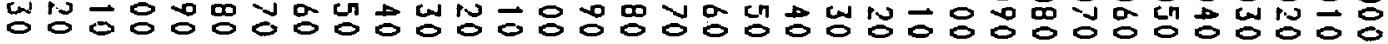

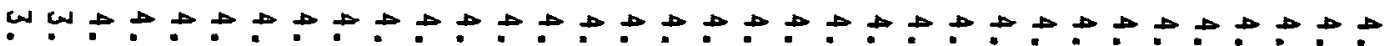

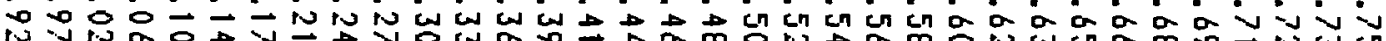

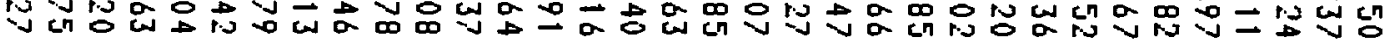
M

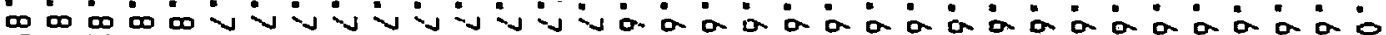
깄 0000000000000000000000000000000000 in in in in in in in in in in in in in in in in in in in in in in in in in in in in in in in in in in

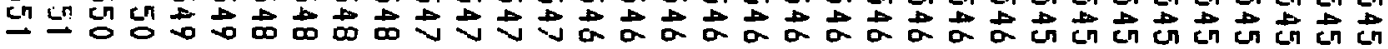

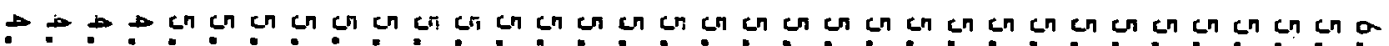
w

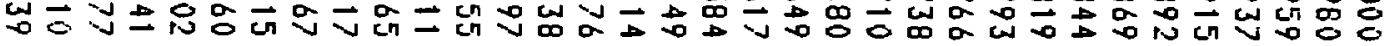

-000000000000000000000000000000000

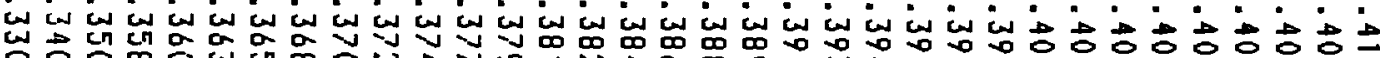

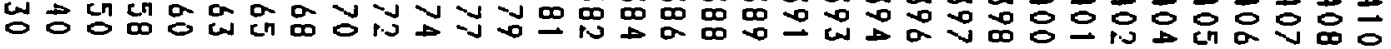
0000000000000000000000000000000000

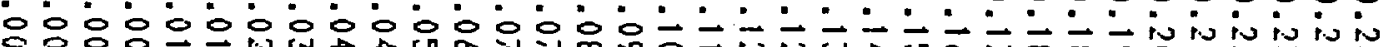
ㅇㅇㅇ이의 0.00000000000000000000000000000000

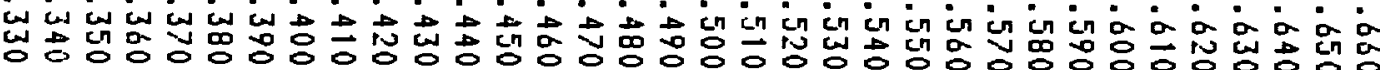

0000000000000000000000000000000000

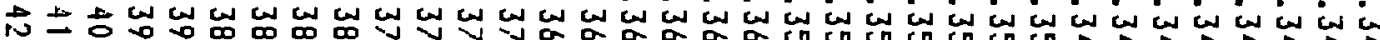

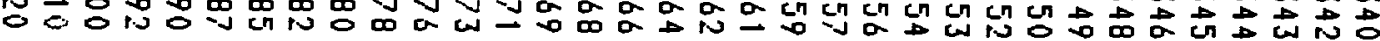
0000000000000000000000000000000000

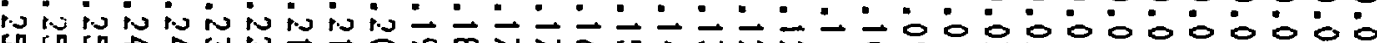
댕댕 -000000000000000000000000000000000

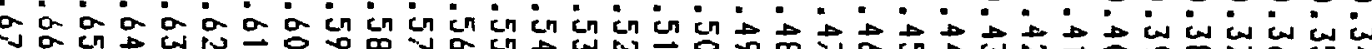

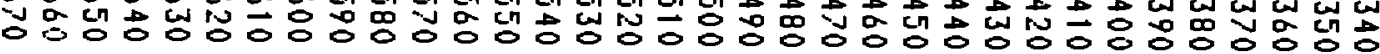

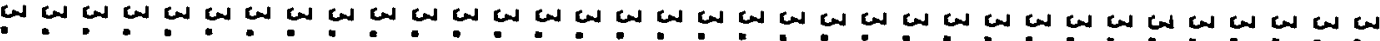

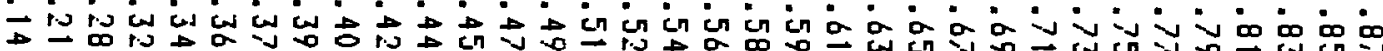

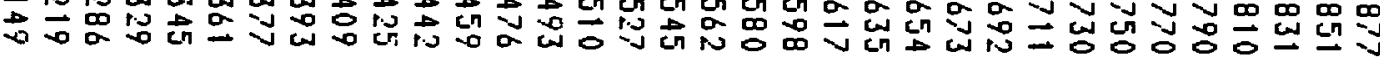

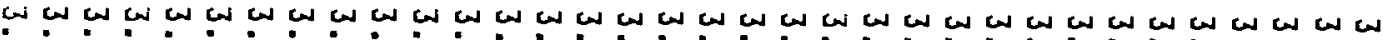
Wis is w w w w

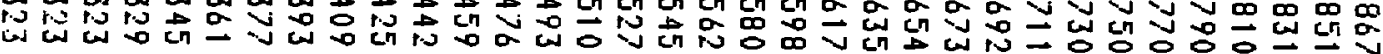
0000000000000000000000000000000000 in in in in in in in in in in in in in in in ir in in ir in in in in in in in in in in in in in in in

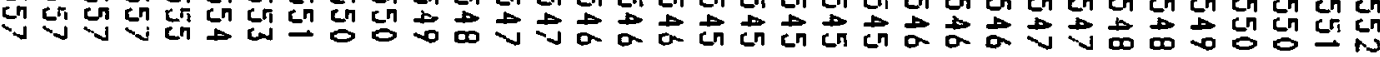
N

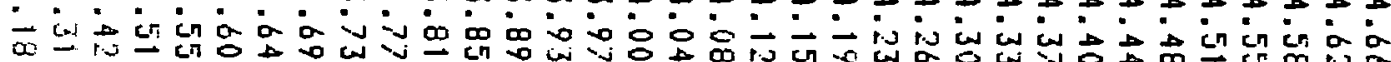

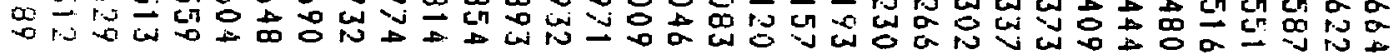

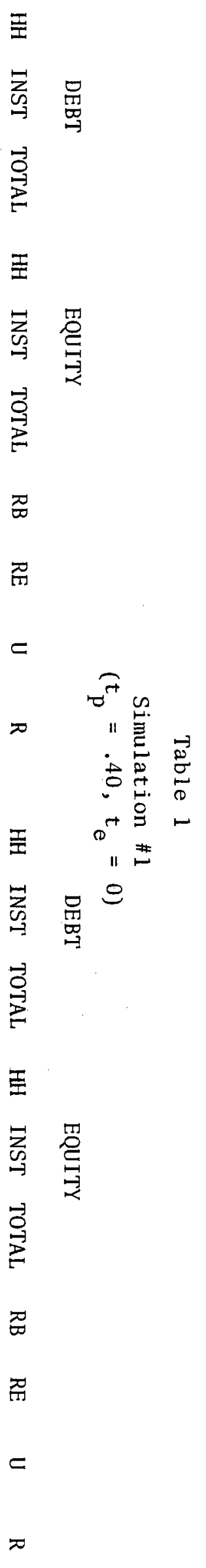


-0,0000000000000000000000000000000

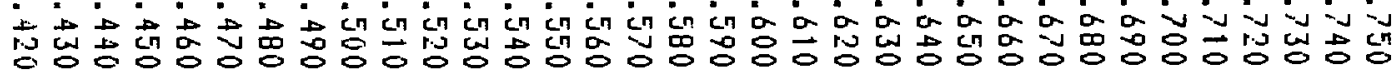
0000000000000000000000000000000000

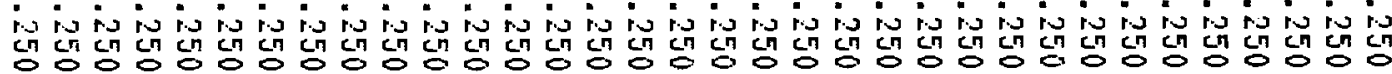
0000000000000000000000000000000001

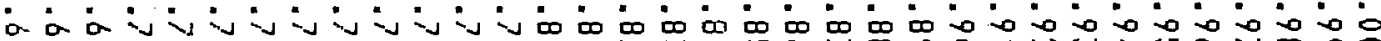

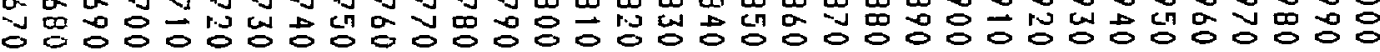

0000000000000000000000000000000000 wiw w w 0000000000000000000000000000000000 0000000000000000000000000000000000

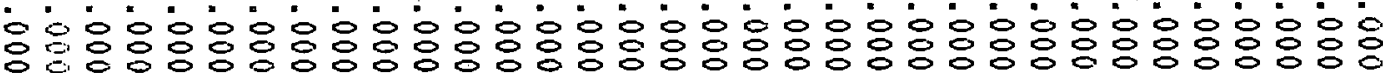
0000000000000000000000000000000000 wiw w

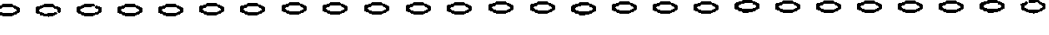

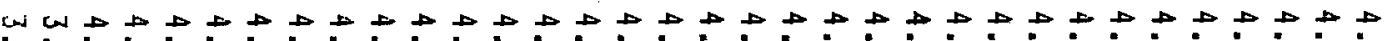

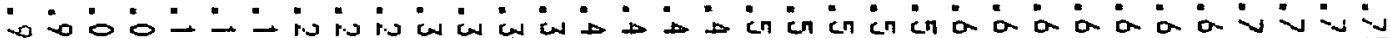

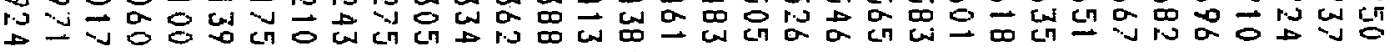

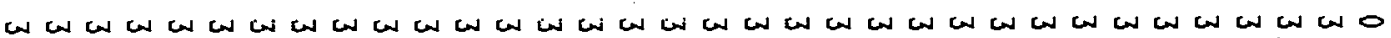

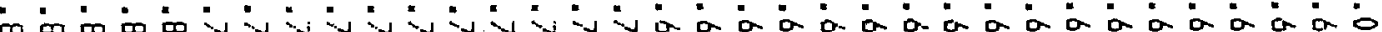

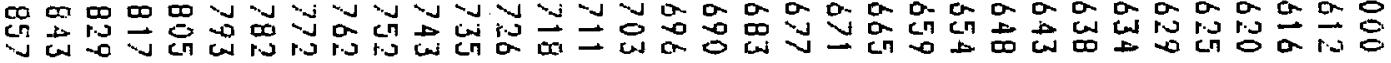
0000000000000000000000000000000000

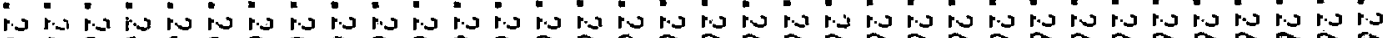

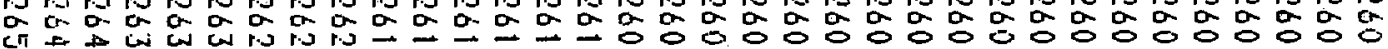

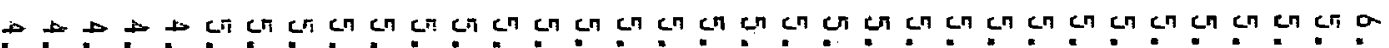

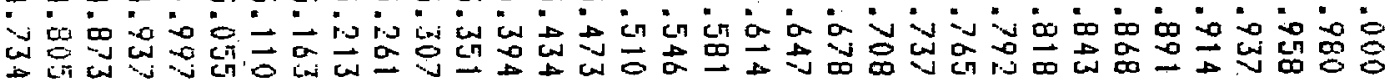

0000000000000000000000000000000000

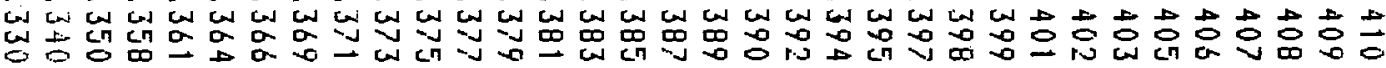
0000000000000000000000000000000000

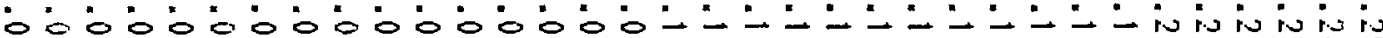

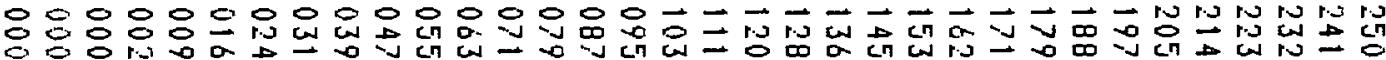
0000000000000000000000000000000000

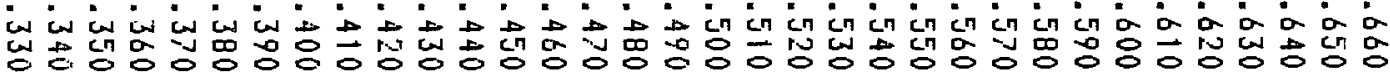

0000000000000000000000000000000000

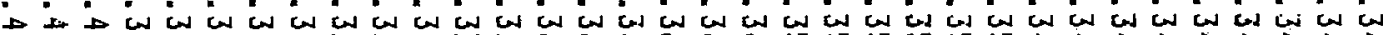

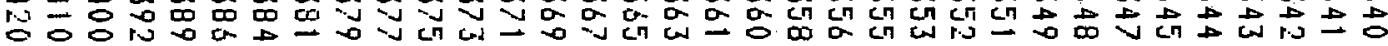
0000000000000000000000000000000000

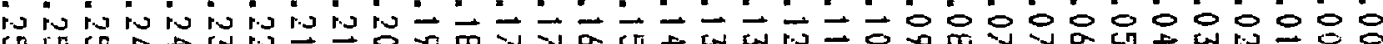

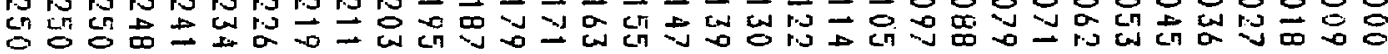
0000000000000000000000000000000000

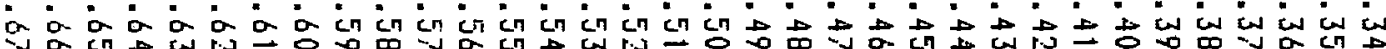

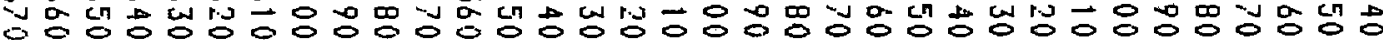

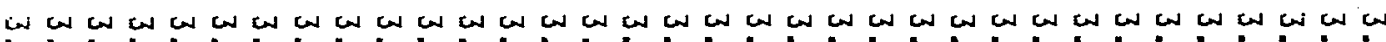

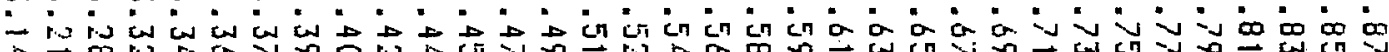

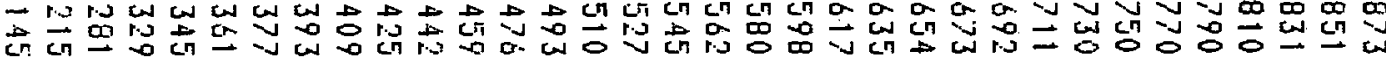
B

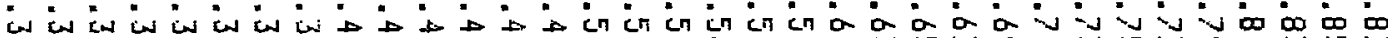
出 0000000000000000000000000000000000

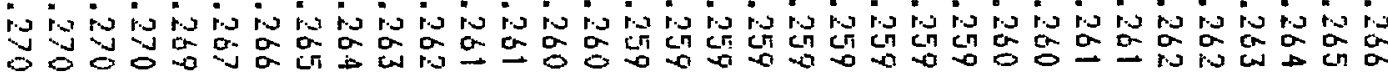

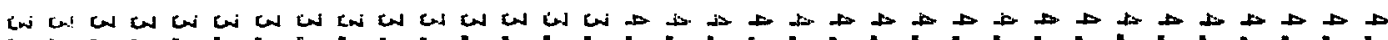

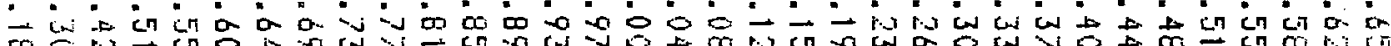

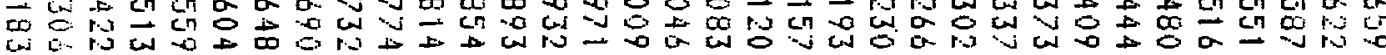

